\title{
Numerical investigations on post-fire bond behaviour of reinforcement
} in concrete

\author{
Arunita Das ${ }^{a^{*},}$ Josipa Bošnjak ${ }^{b}$, Akanshu Sharma $^{\mathrm{a}}$ \\ a Institute of Construction Materials, University of Stuttgart, Pfaffenwaldring 4g, 70569 Stuttgart, Germany \\ b Materials Testing Institute, University of Stuttgart, Pfaffenwaldring 4c, 70569 Stuttgart, Germany
}

Received: 26 March 2019 / Accepted: 26 April 2019 / Published online: 16 May 2019

(C) The Author(s) 2019. This article is published with open access and licensed under a Creative Commons Attribution 4.0 International License.

\begin{abstract}
Reinforced concrete (RC) structures may be subjected to accidental fire loads during their service life. In such a case, it is essential to have appropriate methods for the estimation of post-fire performance. One of the vital aspects for the performance of RC structures is adequate steel-to-concrete bond. The bond behaviour under ambient conditions is very well established. However, an appropriate model for the assessment of the post-fire bond capacity is still lacking. In order to provide more insight into the bond performance after fire, a 3D FE numerical study using a thermo-mechanical model with temperature dependent microplane model for concrete is performed. The effects of concrete cover, confinement through stirrups, fire duration and exposure type on post-fire bond performance are investigated using beam-end specimen. The results show a strong degradation of post-fire bond capacity, which is primarily attributed to the irreversible damage of concrete cover resulting from heating and cooling.
\end{abstract}

Keywords: Steel-to-concrete bond; Temperature dependent microplate model; Beam-end specimen; ISO 834-1 fire curve; Splitting failure

\section{Introduction}

Sufficient bond between concrete and steel is essential for the safe and reliable performance of RC structures/structural elements. Bond behaviour under ambient conditions is very well understood and described. For example, fib Model Code 2010 [1] provides an analytical bond stress-slip relationship (Fig.1) at room temperature. This model differentiates between the two possible failure modes: pull-out (full bond capacity attained) and concrete splitting (full bond capacity not attained). It should be noted that under ambient conditions full concrete pull-out strength cannot be achieved for the majority of cases found in practice (lap slice) i.e. concrete splitting generally governs the bond behaviour. In case of concrete splitting, the model considers the effects of different parameters such as concrete strength, concrete cover, bar diameter and spacing of transverse reinforcement (confinement). Similar provisions can be found in other codes, such as Eurocode 2 [2], $\mathrm{ACl}-318$ [3] etc.

While the guidelines for bond assessment under ambient conditions are well-established, the recommendations for the bond assessment during or after a fire are rather crude. In general, bond degradation upon heating is compared to the degradation of either compressive or tensile concrete strength at elevated temperatures. For example, acc. to fib
Model Code 2010 [1] bond strength degradation can be assumed to correspond to that of tensile strength. Such relatively simplified provisions are based on experimental studies on bond pull-out behaviour using confined test conditions at elevated temperature (slow heating). These tests do not fully capture the realistic boundary conditions that involve fast heating due to fire, low concrete covers and unconfined test setup. Further research is needed to provide a solid basis for the assessment of bond after exposure to fire.

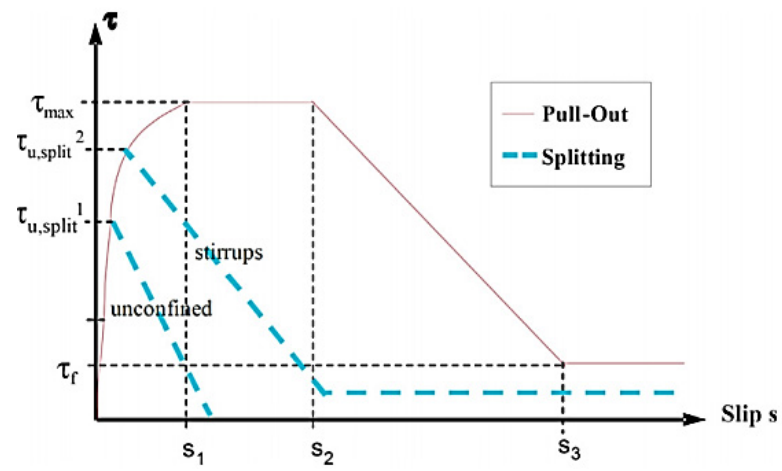

Figure 1. Analytic bond stress-slip relationship for monotonic loading.

* Corresponding author: Arunita Das, E-mail: arunita.das@iwb.uni-stuttgart.de 


\section{Literature review}

Significant research has been performed so far to understand the behaviour of bond at elevated temperatures, mainly focusing on the pure bond failure using RILEM pull-out specimen [4]. In the vast majority of the available experimental studies the specimens were heated slowly to the target temperature and the residual bond capacity was measured either at elevated temperatures or after cooling to room temperature. In this paper, "usable bond capacity" refers to the highest bond stress obtained from any type of failure mode (concrete splitting failure or pure pull-out failure) under ambient conditions. The "residual (usable) bond capacity" refers to the maximum bond capacity obtained after exposure to elevated temperature or fire, independent of the failure mode.

Morley and Royles [5] found that there is an insignificant difference in the degradation of bond strength between specimens tested in hot (at high temperatures) and residual state (after cooling). Moreover, they showed that the presence of a mechanical load (applied before heating) does not significantly influence either hot or residual bond capacity. Several authors reported that the bond degradation after exposure to elevated temperature is roughly comparable to that of the concrete compressive strength, e.g. Hertz [6], Morley and Royles [5], Diederichs and Schneider [7], Bingöl and Gül [8], Lublóy and Balázs [9]. List is only exemplary and not exhaustive. Sager [10] was one of the first to clearly differentiate between pull-out and splitting failure after exposure to elevated temperatures.

More recently, Shamseldein et el. [11] performed experimental investigations on residual bond strength after exposure to elevated temperature using beam-end specimens. Compared to the standard pull-out specimen, the chosen specimen geometry (beam-end specimen) and test setup (unconfined) are more representative of the real conditions in a beam. Specimens with a concrete cover of $\mathrm{c}_{\mathrm{min}}$ $=50 \mathrm{~mm}$ were heated at a slow rate $\left(2^{\circ} \mathrm{C} / \mathrm{min}\right)$ up to $800^{\circ} \mathrm{C}$ and naturally cooled. The reported bond strength degradation corresponds very well to that observed on pullout specimens (approx. 30\% bond retention after exposure to $800^{\circ} \mathrm{C}$ ). Even in case of splitting failure, the residual bond capacity is consistent with that obtained using pull-out specimens.

The experimental results obtained for slow heating regime are useful for the development of temperature dependent material model for pure bond, but do not provide sufficient basis to estimate the post-fire usable bond strength in a structural member.

Recently, Bošnjak et al. [12] investigated the bond behaviour of reinforcement in concrete after fire (standard ISO 834-1 fire [13]) using beam-end specimen. It is concluded that depending on the heating rate and type, thermally induced damage in concrete can lead to a change in failure mode (from pure bond failure to concrete splitting) and a very sharp decrease in the residual bond capacity. The obtained results highlight the importance of the heating rate for residual bond capacity.
The majority of the numerical work performed so far has been limited to phenomenological models, which directly impose the respective bond degradation with temperature. For example, Gao et al. [14] proposed a lower and upper bound of bond capacity at elevated temperature. Using this approach, a numerical study on RC beams subjected to fire was performed. It is reported that the inclusion of bond slightly improves the structural response of the beams under fire. Similarly, Huang [15] proposed a model for bond degradation and validated his approach on beam and pull-out tests. Both studies highlight the need to consider the bond characteristic in a discrete manner, rather than assuming perfect bond conditions. However, this approach does not offer much insight into failure mechanisms and bond capacity.

Sharma et al. [16] performed a numerical study using the 3D thermo-mechanical model with temperature dependent microplane model as constitutive law for concrete. The effect of different parameters influencing the degradation of bond strength in concrete exposed to standard ISO 834-1 fire [13] was investigated using beam-end specimen. It is reported that the effect of thermally induced cracks on post-fire bond capacity is more pronounced compared to that of material degradation due to elevated temperatures.

The work presented herein is a continuation of the same study which includes detailed investigation of several parameters influencing the post-fire bond performance. The analysis is performed for two heating types, namely one-sided and three-sided heating representing the exposure conditions of a slab and a beam under fire, respectively.

\section{Numerical investigations}

In this work, the residual bond capacity is numerically investigated considering following parameters (Table 1):
a) concrete cover
b) spacing of transverse reinforcement (confinement)
c) durations of fire and
d) types of fire exposure

The employed numerical approach was previously validated against several experiments [12]. In this paper, for brevity reasons only failure modes for analysis under ambient conditions and after one-sided exposure to fire are compared to the experimental data.

The numerical study is performed using beam-end specimen geometry. It was previously shown $[12,17]$ that this specimen is more suitable for bond investigation under fire than the standard pull-out specimen. The details of the specimen geometry are provided in the Fig.2. Standard ribbed steel rebar (grade BSt 500) with a diameter of $16 \mathrm{~mm}$ is used. The test rebar is provided with an initial debonded length of $7 d_{s}$ (it is required to prevent concrete cone failure) followed by a bonded length of $8 d_{s}\left(d_{s}\right.$ is diameter of rebar), and a debonded length thereafter. The specimen is internally reinforced with four longitudinal rebar of $12 \mathrm{~mm}$ diameter to prevent concrete cone breakout. Closed stirrups of $8 \mathrm{~mm}$ diameter are provided at a spacing of $100 \mathrm{~mm}$ in the bonded zone. Minimum concrete cover $\left(c_{\min }\right)$ is varied from $1.5 d_{s}=$ 
$24 \mathrm{~mm}$ ) to $3.5 \mathrm{~d}_{\mathrm{s}}=56 \mathrm{~mm}$ (specimens A, B and C). Maximum concrete cover is kept constant at $142 \mathrm{~mm}$. Furthermore, two different stirrup spacing in the bonded zone are considered, namely $100 \mathrm{~mm}$ and $200 \mathrm{~mm}$ (specimens B and D). Normal strength concrete confirming to the grade $\mathrm{C} 16 / 20$ according to Eurocode 2 [3] is considered.

\section{Thermo-mechanical modelling}

The constitutive law used to describe the behaviour of concrete is the temperature dependent microplane model proposed by Ožbolt et al. [18]. As the first step of coupling between mechanical properties of concrete and temperature, the temperature distribution over a solid structure of volume at a given time is calculated by satisfying the energy conservation law. The total strain of concrete at elevated temperatures is decomposed into three components:

$$
\varepsilon_{\text {total }}=\varepsilon_{\mathrm{m}}+\varepsilon_{\mathrm{fts}}+\varepsilon_{\text {lits }}
$$

$\varepsilon_{\text {total }}$ is the total strain, $\varepsilon_{\mathrm{m}}$ is the mechanical strain, $\varepsilon_{\mathrm{fts}}$ is the free thermal strain and $\varepsilon_{\text {lits }}$ is the load induced thermal strain (a strain component that develops when concrete is heated while subjected to compressive stress).

The temperature dependency of the microplane model is adopted such that the macroscopic properties of concrete (Young's modulus, compressive and tensile strength and fracture energy) are temperature dependent.

In a given time step during the incremental nonlinear finite element analysis, the material parameters, as well as the temperature distribution, are assumed to be constant, for more details see [18]. Previous studies [16, 18, 21] have demonstrated the suitability of this modelling approach to realistically capture the behaviour of concrete under fire.

\section{Numerical modelling approach}

The numerical study is performed using the in-house developed 3D finite element software MASA. Concrete is modelled using 4-noded tetrahedral elements and test rebar is modelled using 8-noded hexahedral elements, see Fig.3. The material of the test rebar is considered as linear elastic to reduce computational time and avoid steel yielding. Other longitudinal corner rebars and stirrups are modelled using 2node axial bar elements, for which a trilinear stress-strain law (elasticity modulus, yield strength, hardening modulus and ultimate strength) is defined. Arrangement of the test rebar, stirrups and other longitudinal rebars within concrete are shown in Fig.3c.

The bond between steel and concrete is modelled using 2node bar elements that transfer compression and shear forces. The bond stress-slip law is shown in Fig.4. The values of bond strength of the elements in the bonded and deboned zone are considered as $12 \mathrm{~N} / \mathrm{mm}^{2}$ and $0.1 \mathrm{~N} / \mathrm{mm}^{2}$, respectively.

An overview of the used material properties is provided in Table 2. The temperature dependency of the mechanical and thermal material properties as well as free thermal expansion of the materials are assumed according to Eurocode 2 [19] and Eurocode 3 [20] for concrete and steel, respectively.

Table 1. Matrix for the numerical investigations on beam-end specimens.

\begin{tabular}{|c|c|c|c|c|c|}
\hline \multicolumn{5}{|l|}{ Investigated parameter: Concrete cover } \\
\hline Specimen & Min. clear cover & Rebar diameter $\mathrm{d}_{\mathrm{s}}$ & Stirrup spacing & Duration & Heating type \\
\hline & {$\left[\mathrm{xd}_{s}\right]$} & {$[\mathrm{mm}]$} & {$[\mathrm{mm}]$} & {$[\mathrm{min}]$} & {$[-]$} \\
\hline A & 1.5 & 16 & 100 & $0,30,60$ & 1-and 3-sided \\
\hline B & 2.5 & 16 & 100 & $0,30,60$ & 1-and 3-sided \\
\hline C & 3.5 & 16 & 100 & $0,30,60$ & 1-and 3-sided \\
\hline Investigated parameter: Spacing of transverse reinforcement \\
\hline D & 2.5 & 16 & 200 & $0,30,60$ & 1-and 3-sided \\
\hline
\end{tabular}
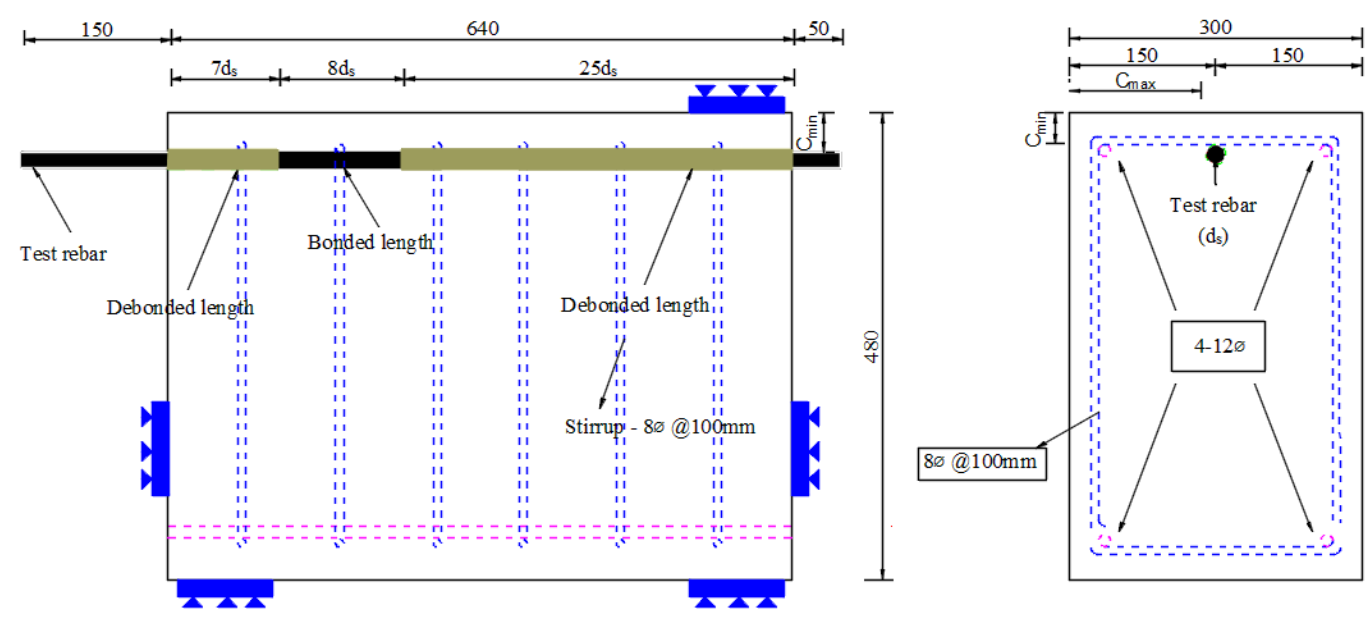

Figure 2. Beam-end specimen. 


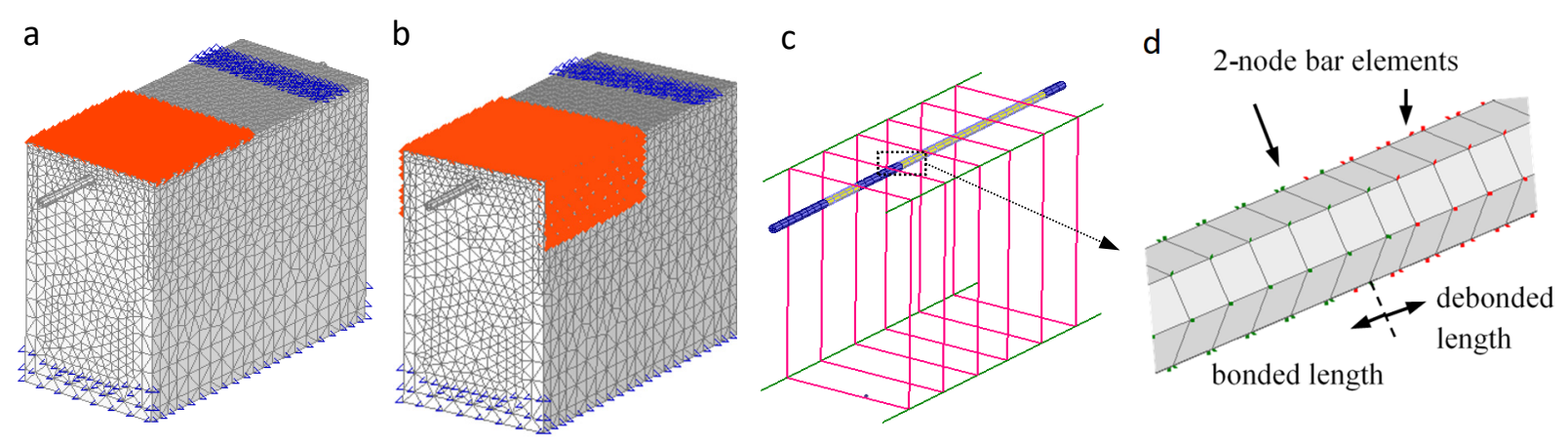

Figure 3. FE model: a) Full model for one-sided heating scenario b) Full model for three-sided heating scenario c) Position of test rebar, other longitudinal rebars and stirrups d) Test rebar with the bond bar elements.

Table 2. Material properties.

\begin{tabular}{|c|c|c|c|c|c|c|}
\hline Material & Compressive strength & Tensile Strength & Elasticity modulus & Poisson's ratio & Fracture energy & Yield Strength \\
\hline & {$\left[\mathrm{N} / \mathrm{mm}^{2}\right]$} & {$\left[\mathrm{N} / \mathrm{mm}^{2}\right]$} & {$[\mathrm{GPa}]$} & {$[-]$} & {$[\mathrm{N} / \mathrm{mm}]$} & {$\left[\mathrm{N} / \mathrm{mm}^{2}\right]$} \\
\hline Concrete & 20 & 2.25 & 23.5 & 0.18 & 0.06 & - \\
\hline Test rebar & - & - & 200 & 0.33 & - & - \\
\hline $\begin{array}{c}\text { Longitudinal } \\
\text { rebars }\end{array}$ & - & 550 & 200 & 0.33 & - & 500 \\
\hline Stirrups & - & 550 & 200 & 0.33 & - & 500 \\
\hline
\end{tabular}

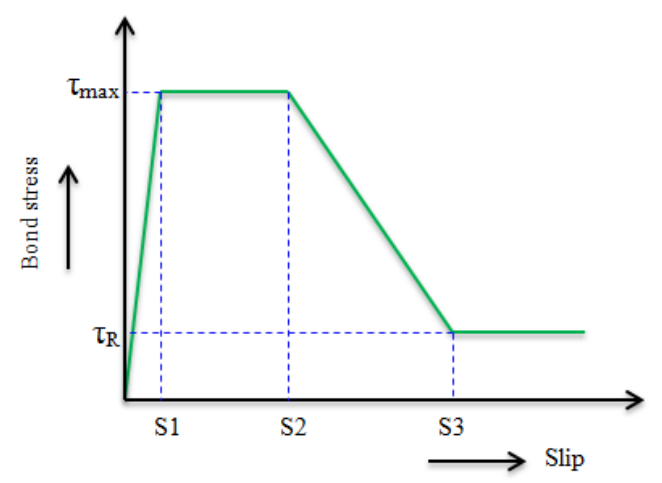

Figure 4. Idealized bond stress-slip relationship used as constitutive law for 2-node bar element.

The increase of air temperature of the concrete is defined by the ISO 834-1 fire curve [13]:

$$
\mathrm{T}=\mathrm{T}_{0}+345 \log _{10}(8 \mathrm{t}+1)
$$

where,

$\mathrm{T}_{0}$ - initial temperature $\left(20^{\circ} \mathrm{C}\right)$

$\mathrm{T}$ - actual temperature in ${ }^{\circ} \mathrm{C}$

$\mathrm{t}$ - time in minutes

Two different exposure types are considered, namely onesided heating and three-sided heating to simulate the exposure conditions in a slab and beam, respectively (Fig.3a and $3 b$ ). In the present study, following fire durations are considered: no fire (reference case), $30 \mathrm{~min}$ and $60 \mathrm{~min}$. Upon exposing to fire for a specific duration, the specimen is cooled to room temperature. Subsequently, the rebar is pulled out in displacement control.
The upper surface of the specimen is constrained towards its rear end perpendicular to the loading direction to prevent any kind of rotation or uplift. The front surface is constrained far from the test rebar towards loading direction to avoid sliding. All the restrains are provided significantly far from the bonded zone to avoid any influence on the pull-out behaviour.

\section{Results}

From the numerical simulation applied load versus slip of rebar is obtained. The slip is monitored at the rear (unloaded) end of the rebar to exclude the elastic elongation of the rebar from the total displacement. The total applied load is then converted to average bond stress over the entire bonded length considering the uniform bond stress approach:

$$
\tau_{b}=\frac{P}{\pi d_{s} l_{b}}
$$

where,

$P$ - total applied tensile load on the rebar

$\mathrm{d}_{\mathrm{s}}$ - diameter of test rebar and

$\mathrm{l}_{b}$ - length of the bonded zone $\left(8 \times d_{s}\right)$

\section{One-sided heating}

The results of the numerical simulations for specimen types A, B, C and D (see Table 1) for one-sided fire exposure are plotted in Fig.5. Under ambient conditions (reference case, no fire exposure) all investigated specimens exhibited concrete splitting, whereby the effective bond capacity decreased with decreasing minimum concrete cover $\left(c_{\min }\right)$. The same failure mode (concrete splitting) is also observed after exposure to fire.

In general, it is found that the fire exposure leads to a significant reduction of the residual bond capacity. This trend 
appears to be similar for all the investigated specimens, almost irrespective of the minimum concrete cover $\left(c_{\min }\right)$. In case of specimen with relatively high concrete cover (specimen $\mathrm{C}$ with $\mathrm{c}_{\min }=56 \mathrm{~mm}$ ), the residual bond strength after $30 \mathrm{~min}$ of fire is only approx. $55 \%$ of that under ambient condition. The reduction in bond capacity is slightly more pronounced (about $40 \%$ residual capacity) for the specimen with a concrete cover of $24 \mathrm{~mm}$ (specimen A with $\mathrm{c}_{\min }=24$ $\mathrm{mm}$ ). The difference in bond capacity for the two considered concrete covers is mainly resulting from the thermal degradation of concrete in the cover region (reduction of concrete strength with temperature). For smaller $c_{\text {min }}$, the temperature within the cover is higher than in case of larger covers, as visible from temperature profiles shown in Fig. 6 (the position of the rebar axis for $c_{\min }=24,40$ and $56 \mathrm{~mm}$ is marked). The material degradation due to elevated temperature is present in concrete independent of the heating type (slow or fast heating, fire etc.).

However, the reduction of concrete strength (with temperature) alone cannot account for the severe degradation of bond capacity after fire, which is observed even in case of relatively high cover $c_{\min }$ and for relatively short fire duration of 30 minutes.

The other cause of bond degradation, which can be more pronounced than material degradation itself, is related to the heating rate. In a fire, the air temperature typically increases very rapidly within a short period of time (e.g. ISO 834-1

a

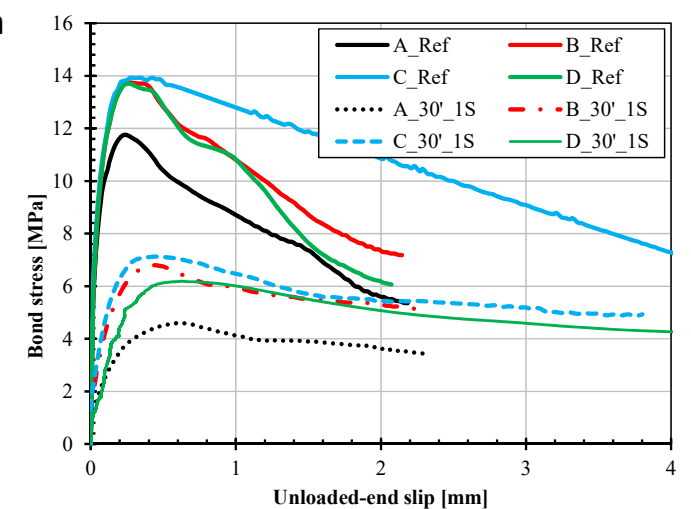

standard fire). As the conductivity of concrete is low, a very high increase of surrounding air temperature leads to a relatively high temperature gradient inside the concrete cover, see Fig.6. This in turn results in a more or less pronounced thermally induced damage (cracks), depending on the severity of fire (heating rate). Cooling of the concrete specimens after fire can further aggravate the damage initiated during heating. It was previously shown by the Bošnjak and Sharma [17] that the level of concrete damage caused by the standard fire is substantially higher than that observed in slowly heated specimens. Thermally induced damage can lead to a significant reduction of the usable bond capacity since thermal cracks promote the formation of the longitudinal splitting crack.

Standard ISO 834-1 fire used in the present study exhibits a rapid temperature rise in the initial phase followed by a moderate temperature increase thereafter. Hence, the bond degradation is very severe even for relatively short fire duration (30 minutes). Upon further heating, bond capacity reduces at a significantly lower rate. After $60 \mathrm{~min}$ the retention of bond capacity lies between 25 and $40 \%$ for all the investigated cases. At this stage, the degradation is again mainly governed by the material degradation due to exposure to elevated temperatures. Due to prolonged exposure to fire, the average temperature in the concrete cover increases, leading to a reduced concrete resistance (strength).

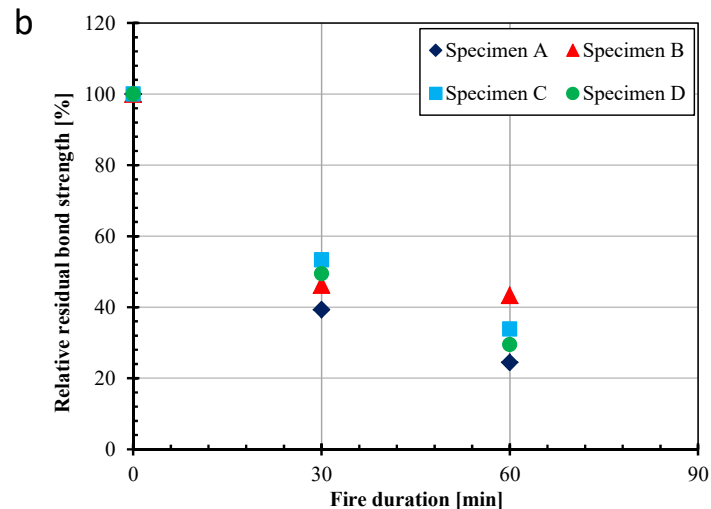

Figure 5. One-sided heating: a) Comparison of bond stress-slip curve obtained from reference tests and after heating (b) Relative residual bond stress for different fire durations.

a

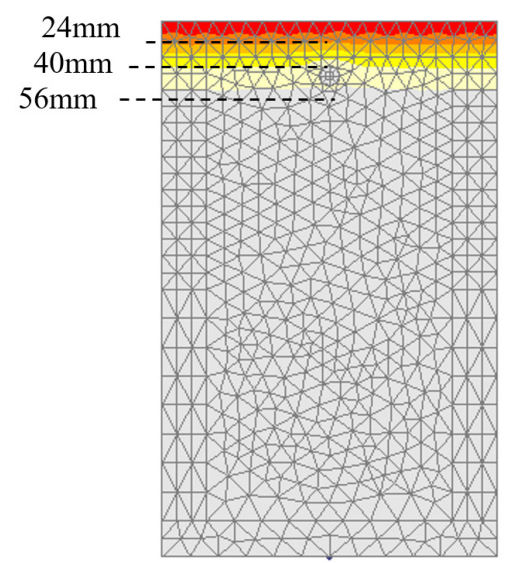

b

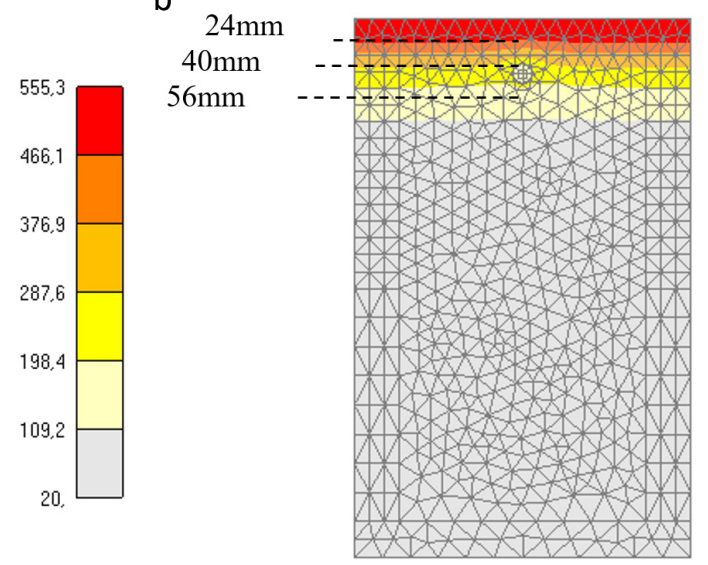

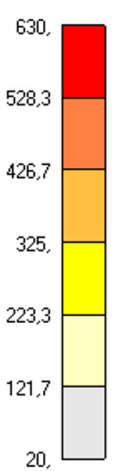

Figure 6. Temperature profile along the cross-section of a specimen with one-sided fire exposure a) after $30 \mathrm{~min}$. and b) after $60 \mathrm{~min}$. of fire. 
The effect of confinement by stirrups is investigated by varying the stirrup spacing in specimen types $B$ and $D$. It can be observed that there is an insignificant difference in the residual bond capacity of the specimen with relatively small amount of transverse reinforcement (stirrup spacing of 200 $\mathrm{mm}$ in the bonded region, specimen D) compared to the specimen with more transverse reinforcement (stirrup spacing of $100 \mathrm{~mm}$ in the bonded zone, specimen B). In relative terms, the effect of stirrup spacing on the bond capacity after exposure to fire remains similar to that under ambient conditions. Even though concrete strength reduces after exposure to fire, the level of confinement by stirrups cannot be increased due to the thermally induced damage.

It is further found that the fire exposure results in a strong degradation of stiffness for all investigated cases. Stiffness is evaluated as secant stiffness at $50 \%$ of the peak stress $\left(k_{50}\right)$ and at peak bond stress $\left(k_{100}\right)$ for all the investigated fire durations. Relative stiffness is then calculated as the ratio between post-fire stiffness (e.g. $k_{50}{ }^{30 \mathrm{~min}}, \mathrm{k}_{100}{ }^{30 \mathrm{~min}}$ ) and corresponding $k_{50}$ stiffness of reference (unheated) specimen (e.g. $k_{50}{ }^{\text {Ref }}$. The results are shown in Fig.7. As discussed above, the dominant effect governing the post-fire bond capacity is the thermally induced damage of the concrete cover. This is confirmed by observing the strong degradation of the stiffness after 30 minutes of fire. Thereafter, the stiffness decreases primarily owing to the increased material degradation (effect of elevated temperature).

\section{Validation against experiments}

The crack patterns obtained numerically and experimentally from the pull-out tests performed on specimens with a minimum concrete cover of $40 \mathrm{~mm}\left(c_{\min }\right)$ are presented in Fig.8. The crack patterns (in terms of principal tensile strain) for the reference specimen and specimen with one-sided

a

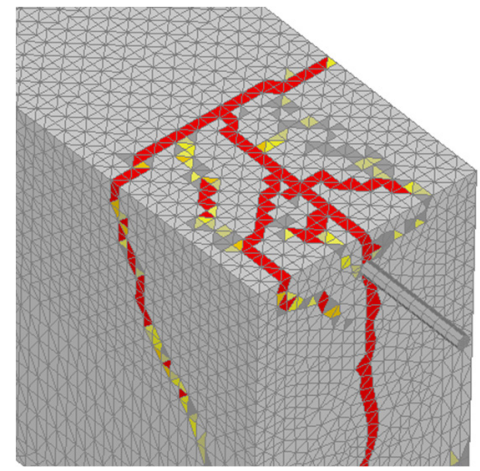

b

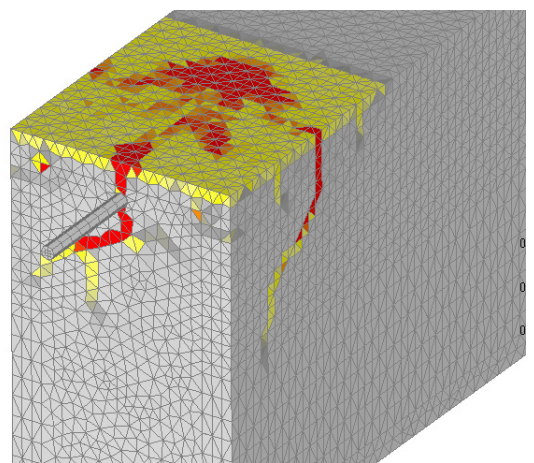

heating for $30 \mathrm{~min}$ of fire are depicted. Red elements in the numerical models represent crack width larger than $0.1 \mathrm{~mm}$, while the red and black lines of the experimental specimens represent thermal cracks and cracks due to mechanical pullout loading, respectively.

A clear transverse crack can be observed at the end of bonded zone due to the tensile failure of concrete. A prominent longitudinal crack parallel to the test rebar can be observed for both the cases as failure occurs due to the splitting of concrete cover prior to bond pull-out. It can be observed that the numerically obtained failure modes are in very good with the experimental findings, thus indicating the suitability of the employed modelling approach for the analysis of bond capacity after fire exposure.

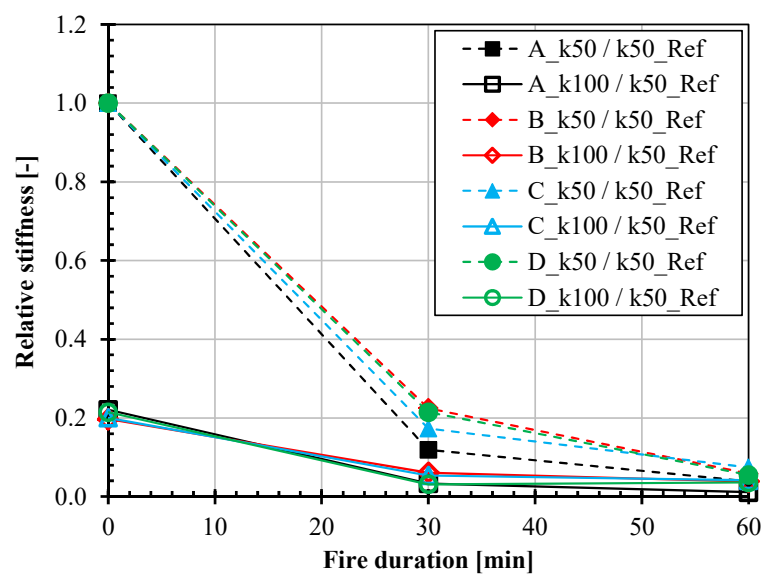

Figure 7. Relative stiffness reduction for one-sided fire exposure.
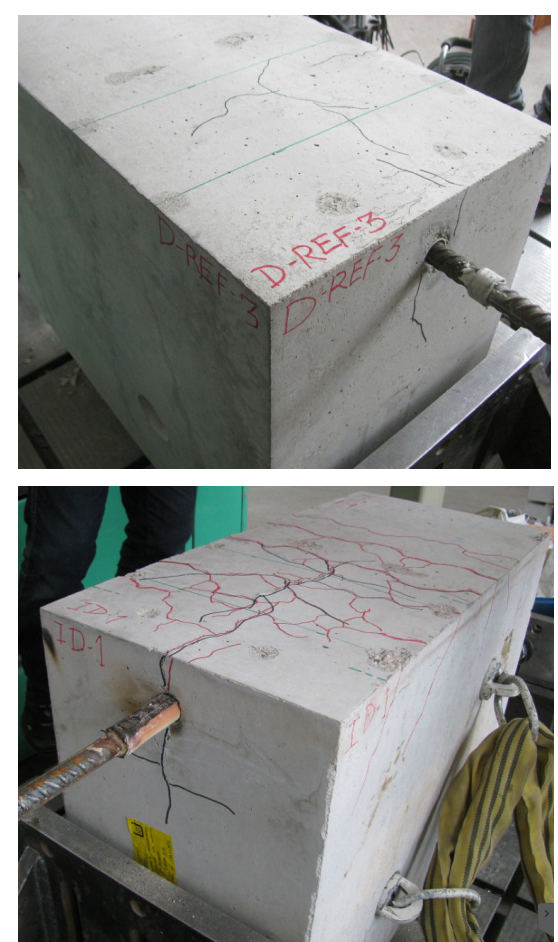

Figure 8. Comparison of numerically and experimentally obtained crack pattern for a) reference specimen b) specimen with one-sided heating (specimen D) after 30 min of fire. 
a

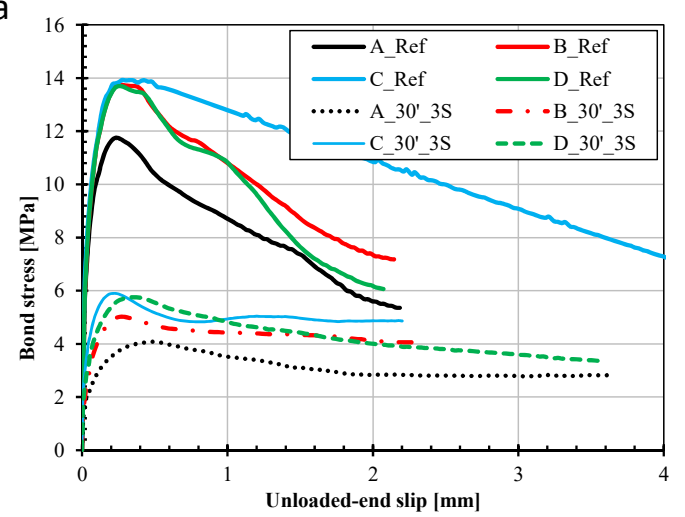

b

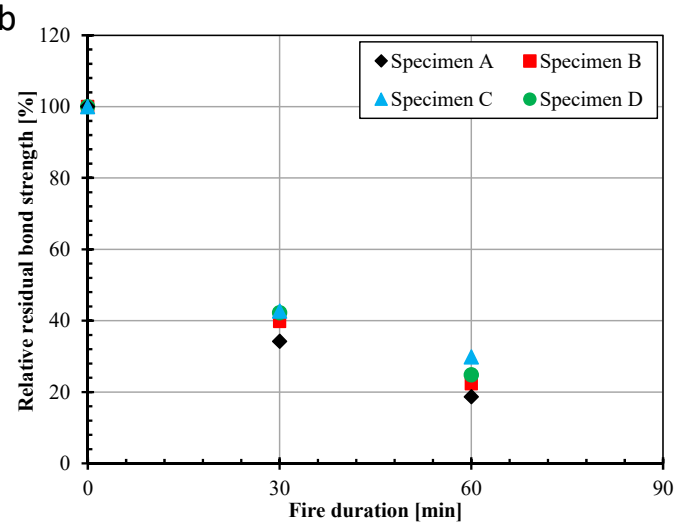

Figure 9. Three-sided heating: (a) Comparison of bond stress-slip curve obtained from reference tests and after heating (b) Relative usable residual bond stress for different fire durations.

\section{Three-sided heating}

The results obtained from the numerical simulations of the pull-out tests performed on beam-end specimens (Specimen type A, B, C and D, see Table 1) exposed to three-sided heating are plotted in Fig.9. In Fig.9a, a comparative study of bond stress vs. unloaded-end slip curve between reference tests and post-fire residual tests is presented, whereas in Fig.9b, relative usable residual bond stress of different specimens after exposing to fire for different durations are depicted. The reduction of relative stiffness with fire is shown in Fig.10.

It is interesting to note that though three sides of the specimens are exposed to fire, there are insignificant differences in terms of degradation of bond strength and secant stiffness as compared to the case of one-sided heating. In the present study $c_{\max }$ is not varied, but due to the change in $c_{\text {min }}$, the ratio $c_{\max } / c_{\min }$ ranged from 2.5 to 5.9. The damage of the concrete cover on the two sides with larger cover $\left(c_{\max }\right)$ has only a minor effect on post-fire bond capacity. The behaviour is dominated by the damage in the smaller concrete cover (thickness of $c_{\text {min }}$ ). It can be observed from the temperature profiles in Fig.11 that three-sided exposure to fire does not contribute towards a greater thermal gradient in concrete. Due to relatively high side cover $\left(c_{\max }\right)$, the maximum temperature around the test rebar is only slightly increased compared to that for one-sided heating. For the fire duration of 60 minutes, the temperature of the concrete cover is somewhat higher than for one-sided heating, resulting in slightly lower bond strength.

Thermally induced cracks appear on the side surfaces (picture omitted for brevity) as well as on the top surface; however, their relative depth (in comparison to $c_{\max }$ ) is insufficient to cause a marked reduction in bond capacity.

Similarly as in case of one-sided heating, relative bond degradation is almost independent of the concrete cover $c_{\text {min }}$ or stirrup spacing.

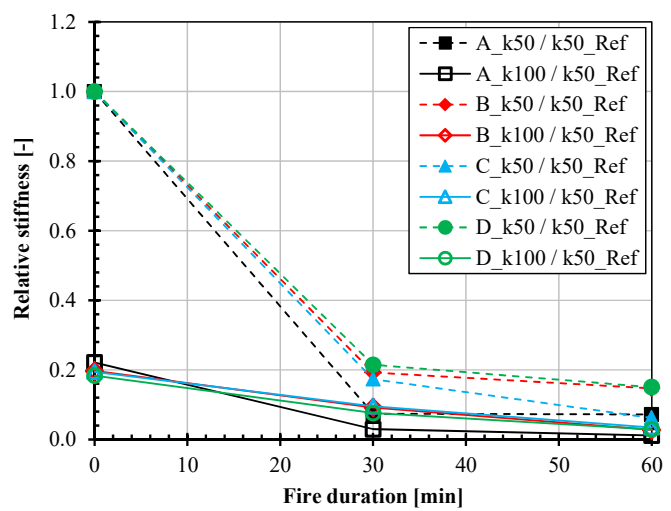

Figure 10. Relative stiffness reduction for three-sided fire exposure.

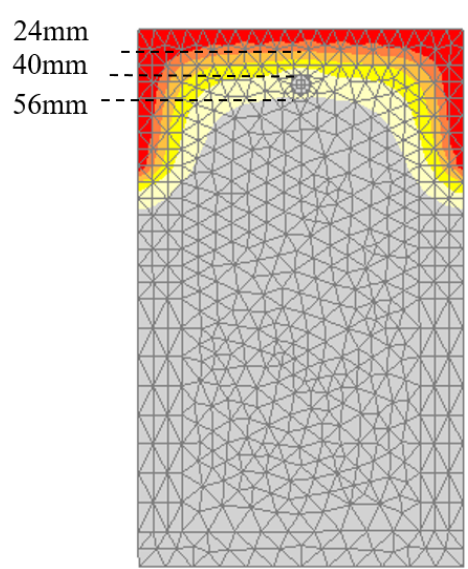

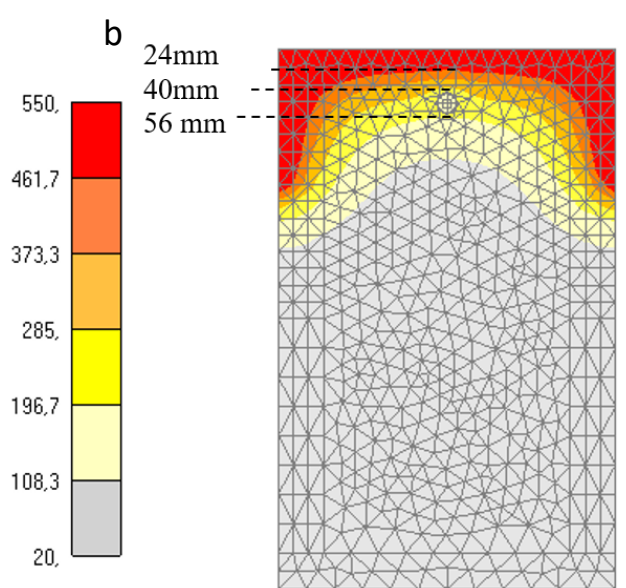

Figure 11. Temperature profile along the cross-section of a specimen with three-sided fire exposure a) after $30 \mathrm{~min}$. and b) after $60 \mathrm{~min}$. of fire. 


\section{Conclusions}

In the work presented herein, numerical investigations are performed on beam-end specimens after exposure to ISO 834-1 fire. The objective of the study was to understand the effect of parameters such as fire duration, concrete cover and confinement level on the post-fire bond capacity. Based on the obtained results, following conclusions can be drawn:

- Exposure to standard fire results in a strong degradation of post-fire bond capacity and stiffness, even for relatively short fire duration of 30 minutes.

- The degradation occurs mainly due to high thermally induced damage (cracks) triggered by temperature gradients in the surface layer of concrete. These cracks facilitate the formation of the longitudinal splitting crack. The severity of thermal cracking is directly linked to the heating rate, hence, this phenomenon is very pronounced in case of fire (as opposed to slow heating typically used in experiments).

- The effect of material degradation due to elevated temperature is shown to have a secondary role in the post-fire bond degradation. Since the material degradation can take place only after concrete attains certain temperature, this phenomenon contributes more towards bond degradation in case of longer fire durations and very small concrete covers.

- The effect of thermal cracking on relative bond degradation can outweigh possible effects of other parameters generally affecting bond. It is found that the relative bond reduction is similar for the investigated range of the cover-to-diameter ratio ( $c_{\min }=1.5$ to $3.5 d_{s}$ ).

- The effect of confinement through stirrups in case of firedamaged specimens is found to be similar to that of nondamaged (reference) specimens.

- The difference in residual bond strength for one- and three-sided heating is relatively small. This is attributed to a relatively high cover ratio $\left(c_{\max } / c_{\min }\right)$ i.e. the behavior is dominated by the damage in smaller concrete cover $c_{\text {min }}$. $\left(c_{\max } / c_{\min }\right.$ ranged from 2.5 to 5.9 ).

\section{Acknowledgments}

The authors gratefully acknowledge the financial support of the German Research Foundation (DFG Grant No. BO 4810/1-1).

\section{References}

[1] fib Model Code for Concrete Structures 2010, Vol.55 Ernst \& Sohn (2013). https://doi.org/10.1002/9783433604090

[2] EN 1992-1-1:2004, Eurocode 2: Design of concrete structures - Part 1-1: General rules and rules for buildings, European Committee for Standardization, 2004.

[3] $\mathrm{ACl} 318$ Standard Building Code: Building code requirements for structural concrete and commentary, American Concrete Institute, 1995.

[4] RILEM. Recommendations for the testing and use of construction materials. RILEM (1994) 12: 213-220.

[5] P. Morley, R. Royles, Response of bond in reinforced concrete to high temperature. Mag Concr Res (1983) 35:67-74. https://doi.org/10.1680/macr.1983.35.123.67

[6] K. Hertz, The anchor capacity of reinforcing bars at normal and high temperatures. Mag Concr Res (1982) 34: 213-20. https://doi.org/10.1680/macr.1982.34.121.213
[7] U. Diedrichs, U. Schneider, Bond strength at high temperature. Mag Concr Res (1981) 33:75-84.

https://doi.org/10.1680/macr.1981.33.115.75

[8] AF. Bingöl, R. Gül, Residual bond strength between steel bars and concrete after elevated temperature. Fire Saf J (2014) 69:23-35. https://doi.org/10.1016/j.firesaf.2014.07.001

[9] E. Lublóy, G. Balázs, Temperature effects on bond between concrete and reinforcing steel. Zbornik radova Građevinskog fakulteta (2014) 30:27-35. https://doi.org/10.14415/zbornikGFS26.03

10] H. Sager, Zum Einfluss hoher Temperaturen auf das Verbundverhalten von einbetonierten Bewhrungsstäben, PhD Thesis, Technical University of Braunschweig (1985).

[11] A. Shamseldein, H. Elshafi, A. Rashad, M. Kohail, Assessment and restoration of bond strength of heat-damaged reinforced concrete elements. Constr Build Mater (2018) 169: 425-435. https://doi.org/10.1016/j.conbuildmat.2018.03.008

[12] J. Bošnjak, A. Sharma, C. Öttl, Modified beam-end test setup to study the bond behavior of reinforcement in concrete after fire. Mater Struct (2018) 51:13.

https://doi.org/10.1617/s11527-018-1138-7

[13] ISO 834-1: Fire-resistance tests - Elements of building construction Part 1: General requirements, Geneva (Switzerland), International Organisation for Standardisation, 1999.

[14] WY. Gao, JG. Dai, JG. Teng, GM. Chen, Finite element modeling of reinforced concrete beam exposed to fire. Eng Struct (2013) 52:488501. https://doi.org/10.1016/j.engstruct.2013.03.017

[15] Z. Huang, Modelling the bond between concrete and reinforcing steel in a fire. Eng Struct (2010) 32:3600-3669. https://doi.org/10.1016/i.engstruct.2010.08.010

[16] A. Sharma, J. Bošnjak, J. Ožbolt, J. Hofmann, Numerical modelling of reinforcement pull-out and cover splitting in fire exposed beam-end specimens. Eng Struct (2016) 111:217-232. https://doi.org/10.1016/i.engstruct.2015.12.017

[17] J. Bošnjak, A. Sharma, Bond between steel and concrete under fire from laboratory tests to fire performance. Proc. 3rd Int Symp on Connect between Steel and Concr, Stuttgart (Germany) 27-29 September 2017, IWB University of Stuttgart, 2017, 826-837.

[18] J. Ožbolt, I. Kožar, R. Eligehausen, G. Periškić, Instationäres 3D Thermo-mechanisches Modell für Beton. Beton- Stahlbetonbau (2005) 100:39-51. https://doi.org/10.1002/best.200590006

[19] EN 1992-1-2:2004, Eurocode 2: Design of concrete structures - Part 1-2: General rules- Structural fire design, European Committee for Standardization, 2004.

[20] EN 1993-1-2:2004, Eurocode 3: Design of steel structures - Part 1-2: General rules- Structural fire design, European Committee for Standardization, 2005.

[21] J. Ožbolt, J. Bošnjak, G. Periškić, A. Sharma, 3D numerical analysis of reinforced concrete beams exposed to elevated temperature. Engineering Structures (2014) 58:166-174. https://doi.org/10.1016/j.engstruct.2012.11.030 